\title{
NATIONALISM INSIDE THE POEM OF "DIPONEGORO" BY CHAIRIL ANWAR A HISTORICAL STUDY
}

\author{
Kinayati Djojosuroto
}

Email: kinayati_dj@yahoo.com

Fakultas Bahasa dan Seni Universitas Negeri Manado

Alamat Koresponden : Jl. Swasembada Barat Gang XIX no.40 Tanjungpriok Jakarta 14320

\begin{abstract}
This study aims to reveal the meaning of the elements of nationalism in the poem "Diponegoro" by Chairil Anwar and to reveal the relationship between the poetry of "Diponegoro" with the history of Diponegoro War (Java War) in 1825 - 1830. The "Diponegoro" poem is one of the phenomenal works that, if the contents are reviewed, alive and exist in a fighting spirit, the spirit of nationalism. In this postmodern era, the poetry of 'Prince Diponegoro' by Chairil Anwar is still exist as poem which fights for its country. The method used in this research is descriptive qualitative with content analysis techniques. Conclusion: 1. Poetry "DIPONEGORO" is the poem with struggling spirit. In this case, it was the fight of Diponegoro against the Netherlands' colonialism. His nationalism, his love and obedience, his loyalty for his country, had led Diponegoro onto resistance because he wanted to liberate his people, from the domination and the grip of foreign power, the Netherlands. 2. The poem of "Diponegoro" cannot be separated from the history of the past, the resistance of the people of Java against the Netherlands' colonialism.
\end{abstract}

Keywords: Poem, Nationalism, Diponegoro, Java War, Historical Study

\section{PENDAHULUAN}

$\begin{array}{ccc}\text { Puisi-puisi } & \text { karya } & \text { Chairil } \\ \text { Anwar walaupun sudah sangat lama }\end{array}$ diciptakan, namun masih banyak digemari oleh masyarakat umum bahkan masih tetap dipelajari di sekolah-sekolah. Banyak puisi karya beliau yang sangat fenomenal, diantaranya Puisi "Diponegoro". Dalam Puisi "Diponegoro", Chairil Anwar menggambarkan perjuangan Diponegoro dalam medan perang, berjuang demi tanah air dan kemerdekaan. Beliau tak gentar meskipun musuh jauh lebih banyak. Puisi perjuangan chairil Anwar hingga saat ini masih tetap menjadi motivasi bagi generasi penerus bangsa.

Puisi "Diponegoro" merupakan salah satu karya fenomenal yang jika ditelaah isinya tetap hidup dan eksis dalam semangat perjuangan, semangat nasionalisme. Diponegoro dengan predikat Sang Pangeran seolah masih tetap hidup dan berjuang untuk memperjuangkan bangsanya. Chairil Anwar begitu semangat menulis puisi "Diponegoro" untuk menghormati jasa pahlawan Diponegoro melalui puisi yang ia ciptakan. Dengan kemampuannya menulis puisi, ia menggunakan kata dan kalimat yang teratur, kalimat yang sederhana dalam mengungkapkan semangat juang nasionalisme. Hingga saat ini eksistensi puisi "Diponegoro" masih terasa pas untuk kehidupan bangsa Indonesia. Puisi ini menunjukkan suatu bentuk perwujudan kenasionalismean Chairil pada bangsa Indonesia.

Puisi "Diponegoro" yang digubah Chairil Anwar ini sangat menggugah batin bangsa Indonesia karena puisi ini merupakan suatu perjuangan yang dilakukan oleh seorang pejuang yang nasionalis. Betapa gagah beraninya pejuang tersebut hingga ia rela berkorban dengan menempati barisan paling depan untuk melawan musuh (Belanda) yang jumlahnya sangatbanyak. Puisi "Diponegoro" dapat menginspirasi bahwa pada zaman sekarang dibutuhkan seseorang yang dapat 
menjadi pimpinan seutuhnya. Dalam masa pembangunan ini dibutuhkan sosok seperti Diponegoro yang punya semangat juang, nasionalis sejati, sebagai bara yang siap menjadi nyala api berkobar. Pangeran Diponegoro adalah pahlawan bangsa yang pantas untuk kita teladani. Di masa pembangunan seperti saat ini semangat perjuangan Pangeran Diponegoro harus dihidupkan kembali dalam jiwa kita sebagai penerus perjuangan bangsa. Diponegoro adalah sosok pahlawan yang gagah berani dan nasionalis. Ada beberapa tokoh di Indonesia saat ini yang nasionalis tapi mungkin takut berkorban dalam perjuangan, sedangkan Pangeran Diponegoro memiliki sifat nasionalis yang berani mati bagi bangsanya.

Puisi "Diponegoro" telah menunjukkan kecintaan Chairil Anwar kepada bangsa Indonesia dan kepada pahlawan Diponegoro. Bangsa yang besar adalah bangsa yang mengingat dan menghargai perjuangan para pendahulunya. Bukan emas dan uang yang mampu membuat suatu bangsa menjadi besar dan jaya. Manusia-manusia yang bertekad dan bersedia lama menderita demi kebenaran dan kehormatan bangsanyalah yang mampu membuat suatu bangsa besar dan jaya. Melalui tulisan ini penulis ingin mengangkat kembali Diponegoro sebagai pejuang, sebagai seorang nasionalis, sebagai pahlawan dalam sejarah Indonesia. Hal ini merupakan kenangan dan penghormatan terhadap perjuangannya lewat puisi Chairil Anwar. Perjuangan, ketabahan, kenasionalismean Diponegoro dapat menjadi suri teladan buat anak cucu nanti dalam membangun kesatuan bangsa. Tak salah jika waktu lampau Bung Karno pernah berucap JASMERAH (Jangan Melupakan Sejarah).

Untuk itulah pada tulisan ini penulis akan membahas puisi "Diponegoro" dengan menggunakan pendekatan historis karena puisi "Diponegoro" tidak terlepas dari perang Jawa (Java War) tahun 1825-1830. Pendekatan historis adalah pendekatan yang meninjau suatu permasalahan dari sudut tinjauan sejarah, dan menjawab permasalahan serta menganalisisnya dengan menggunakan bukti-bukti sejarah. Pendekatan historis adalah studi yang berhubungan dengan peristiwa-peristiwa sejarah atau kejadian masa lalu yang menyangkut kejadian atau keadaan yang sebenarnya. Sejarah selalu berhubungan dengan peristiwa-peristiwa masa lalu, namun peristiwa masa lalu tersebut hanya berarti bila dipahami dari sudut tinjauan masa kini. Para ahli sejarah dapat benar-benar memahami peristiwa atau kejadian masa kini hanya dengan petunjukpetunjuk dari peristiwa kejadian masa lampau tersebut.

Berdasar pada latar belakang di atas maka peneliti memberi judul makalah ini ; Nasionalisme Dalam Puisi “Diponegoro" Karya Chairil Anwar, Suatu Kajian Historis

\section{Rumusan Masalah:}

1. Bagaimanakah penggambaran unsurunsur nasionalisme dalam puisi "Diponegoro" karya Chairil Anwar?

2. Apakah puisi "Diponegoro" terkait dengan sejarah Perang Diponegoro (Java War) tahun 1825-1830?

\section{Tujuan Penulisan}

1. Mengungkap makna yang mendalam tentang unsur-unsur nasionalisme dalam puisi "Diponegoro" karya Chairil Anwar.

2. Mengungkap makna yang mendalam tentang keterkaitan puisi "DIPONEGORO" dengan sejarah Perang Diponegoro (Java War) tahun 1825-1830.

\section{METODE}

Penelitian ini menggunakan metode deskriptif kualitatif dengan pendekatan historis.

\section{LANDASAN TEORETIS \\ Pedekatan Historis}

Historis yang berlandaskan ilmu sejarah adalah suatu ilmu yang didalamnya dibahas berbagai peristiwa dengan memperhatikan unsur tempat, waktu, objek, latar belakang, dan pelaku dari peristiwa tersebut. Menurut ilmu ini segala peristiwa dapat dilacak dengan melihat kapan peristiwa itu terjadi, dimana, apa sebabnya, dan siapa yang terlibat dalam peristiwa tersebut.

Melalui pendekatan historis seseorang akan diajak menukik dari alam idealis ke alam yang bersifat empiris dan mendunia. Dari keadaan ini seseorang akan melihat adanya kesenjangan atau keselarasan antara yang terdapat dalam alam idealis dengan yang ada di alam empiris dan historis. Histori atau 
sejarah adalah suatu ilmu yang di dalamnya dibahas berbagai peristiwa dengan memperhatikan unsur tempat, waktu, objek, latar belakang dan pelaku peristiwa tersebut. Unsur-unsur tersebutlah yang dinamakan dengan kondisi historis-sosial-budaya.

Adapun yang dimaksud dengan pendekatan disini adalah cara pandang atau paradigma yang terdapat dalam suatu bidang ilmu yang selanjutnya digunakan dalam memahami karya sastra dalam hal ini puisi. Defenisi serupa diungkapkan oleh Abd. ArRahman Sakhawi (2000, h. 10) bahwa sejarah adalah seni yang berkaitan dengan serangkaian anekdot yang berbentuk kronologi peristiwa.. Sejarawan Louis Gottschalk dalam bukunya Understanding History: a Primer of Historical Method, (200, h.5) menjelaskan pengertian sejarah. Sejarah dalam bahasa Inggris history berasal dari kata benda Yunani istoria yang berarti ilmu. Dalam penggunaannya oleh filosof Yunani, Aristoteles, istoria berarti suatu penjelasan sistematis mengenai seperangkat gejala alam, baik susunan kronologi yang merupakan faktor atau tidak di dalam bahasa Inggris sebutan natural history. Akan tetapi, dalam perkembangan zaman, kata latin yang sama artinya scientia, lebih sering dipergunakan untuk menyebutkan penjelasan sistematis nonkronologis mengenai gejala alam; sedangkan kata istoria biasanya dipergunakan bagi penjelasan mengenai gejala-gejala (terutama hal ihwal manusia) dalam urutan kronologis. Adapun menurut defenisi yang umum, kata history kini berarti masa lampau umat manusia. Sejarawan Indonesia, seperti Sartono dalam bukunya "Pendekatan Ilmu Sosial dalam Metodologi Sejarah", membagi pengertian sejarah pada pengertian subjektif dan objektif. (Sartono Kartodirdjo, 1993, h. 14-15).

Sejalan dengan pemikiran Sartono, sejarawan Zakiah berpendapat, melalui pendekatan historis ini seorang diajak untuk memasuki keadaan yang sebenarnya berkenaan dengan penerapan suatu peristiwa. (Zakiah Drajat,1996:1) Selanjutna Zakiah mengemukakan bahwa, pandangan historis adalah suatu pandangan umum tentang pandangan metode pengajaran secara suksesif sejak dulu sampai sekarang dan akan diiringi secara sepintas lalu mengenai problematik metodologi itu.

\section{Pendekatan Historis dalam Karya sastra}

Nisa Ahmed mengatakan bahwa Pendekatan Historis adalah suatu pendekatan yang menekankan pada pemahaman tentang biografi pengarang, latar belakang peristiwa kesejarahan yang melatarbelakangi masamasa terwujudnya cipta sastra yang dibaca serta tentang bagaimana perkembangan kehidupan penciptaan maupun kehidupan sastra itu sendiri pada umumnya dari zaman ke zaman (Nisa Ahmed Faruqi, 1979, h.3)

Prinsip dasar yang melatarbelakangi lahirnya pendekatan ini adalah anggapan bahwa cipta sastra bagaimanapun juga merupakan bagian dari zamannya. Selain itu, pemahaman terhadap biografi pengarang juga sangat penting dalam upaya memahami kandungan dalam suatu cipta sastra. Sebab itulah telaah makna suatu teks dalam pendekatan historis sangat mengutamakan konteks, baik konteks sosio-budaya, situasi atau zaman maupun konteks kehidupan pengarangnya sendiri. Dalam telaah karya sastra lewat pendekatan historis ini, pembaca dapat memanfaatkan berbagai informasi kesejarahan tambahan, pembaca juga dapat melihat pada keterangan tentang biografi pengarang yang terdapat dibagian belakang maupun esei-esei tentang kehidupan pengarang yang terdapat dalam buku-buku kumpulan karangan maupun majalah dan koran.

Penyebab utama lahirnya karya sastra adalah penciptanya sendiri yaitu sang pengarang. Itulah sebabnya penjelasan tentang kepribadian dan kehidupan pengarang adalah metode tertua dan paling mapan dalam studi sastra. Biografi hanya bernilai sejauh memberi masukan tentang penciptaan karya sastra.Tetapi biografi juga dapat dinikmati karena mempelajari hidup pengarang yang jenius, menelusuri perkembangan moral, mental, dan intelektualnya yang tentu menarik.

\section{Nasionalisme}

Nasionalisme adalah paham yang menciptakan dan mempertahankan kedaulatan sebuah negara yang dalam bahasa Inggrisdisebut nation dengan mewujudkan satu konsep identitas bersama untuk 
sekelompok manusia. Koentjaraningrat, dalam bukunya Masalah Kesukubangsaaan dan Integrasi Nasional. (199, h.20) mengatakan secara umum, dalam konteks Indonesia, nasionalisme adalah perasaan cinta dan taat, setia kepada tanah air dan ingin membebaskan negara dan bangsanya dari penguasaan dan cengkeraman kuasa asing. Selanjutnya dikatakan bahwa nasionalisme juga ada kaitan dengan "negara" dan "bangsa". Nasionalisme pada umumnya bertujuan mewujudkan kebebasan individu dan negara dari cengkeraman dan kungkungan pemerintah serta kuasa asing. Nasionalisme adalah satu ideologi yang mencipta dan mempertahankan kedaula tan sebuah _negara dengan mewujudkan satu konsep identitas bersama untuk sekumpulan manusia.

Nasionalisme adalah sebuah tuntutan politik. Setiap bangsa berhak menuntut kedaulatan atas negeri tempatnya tinggal selama berabad-abad berdasarkan alasanalasan budaya, ekonomi dan kemasyarakatan. Kuntowijoyo menjelaskan, walaupun persatuan Indonesia telah bertunas lama dalam sejarah bangsa Indonesia, akan tetapi semangat kebangsaan atau nasionalisme dalam arti yang sebenarnya seperti kita pahami sekarang ini, secara resminya baru lahir pada permulaan abad ke-19. Ia lahir terutama sebagai reaksi atau perlawanan terhadap kolonialisme dan karenanya merupakan kelanjutan dari gerakan-gerakan perlawanan terhadap kolonial VOC dan Belanda, yang terutama digerakkan oleh rajaraja dan pemimpin-pemimpin agama Islam. Rakyat juga diperas dan dipaksa bekerja untuk kepentingan ekonomi kolonial, misalnya seperti terlihat sistem tanam paksa (culturstelsel) yang diterapkan pemerintah Hindia Belanda di Jawa pada awal abad ke-18 dan menimbulkan perlawanan seperti Perang Diponegoro (Java war). Karena itu nasionalisme Indonesia hadir untuk menghentikan eksploitasi ekonomi asing dengan berdikari. (Kuntowijoyo, 1994, h.25)

\section{Nasionalisme dalam Puisi "Diponegoro" Karya Chairil Anwar}

\section{Teks Puisi}

\section{DIPONEGORO \\ (Chairil Anwar)}

Di masa pembangunan ini
tuan hidup kembali
dan bara kagum menjadi api

Di depan sekali tuan menanti

Tak gentar. Lawan banyaknya seratus kali.

Pedang di kanan, keris di kiri

Berselempang semangat yang tak bisa mati.

MAJU

Ini barisan tak bergenderang-berpalu

Kepercayaan tanda menyerbu.

Sekali berarti

Sudah itu mati.

MAJU

Bagimu Negeri

Menyediakan api.

Punah di atas menghamba

Binasa di atas ditindas

Sesungguhnya jalan ajal baru tercapai

Jika hidup harus merasai

$$
\begin{gathered}
\text { Maju } \\
\text { Serbu } \\
\text { Serang } \\
\text { Terjang }
\end{gathered}
$$

(Februari 1943) Anwar, Chairil. Deru Campur Debu. (1977, h. 15)

\section{PEMBAHASAN \\ Nasionalisme}

Puisi di atas bertemakan pejuangan. Dalam hal ini, perjuangan Diponegoro adalah perjuangan melawan kolonialisme. Rasa nasionalis,rasa cinta dantaat, setia kepada tanah air, menyebabkan Diponegoro melakukan perlawanankarena ingin membebaskan negara dan bangsanya dari penguasaandan cengkaman kuasa asing dalam hal ini Belanda.

Peranan Chairil Anwar sebagai perekam sejarahPerang Diponegoro merupakan rekaman kejadian nyata dimana pada perang tersebut rakyat Indonesia hanya bermodalkan tekad untuk diakui sebagai manusia yang merdeka.Tentu saja lawannya adalah penjajah yang bersenjata pelor, lengkap dan didukung kemampuan militer yang kuat. Puisi tersebut 
di atas merupakan rekonstruksi perasaan dan semangat yang berkobar pada perang tersebut, kemudian Chairil Anwar merekonstruksi perasaan dan semangat itu dalam bentuk kata-kata, larik, dan bait.

//Sekali berarti, sudah itu mati//,larik ini menggambarkan nasionalisme yang tinggi, tegas, penyemangat hidup. Hidup hanya sekali, sudah itu mati, sebab itu berilah arti hidup ini demi bangsa dan negara. Ada pepatah yang mengatakan "gajah mati meninggalkan gadingnya, manusia mati meninggalkan namanya." Hidup harus rela dan ikhlas. Hal ini jelas terkandung dalam larik: // Sesungguhnya jalan ajal baru tercapai//Larik ini menjelaskan bahwa dalam kehidupan ini seharusnya menjalankan semua kebaikan sampai akhir hayat, walau kita tidak dapat menikmatinya, namun generasi penerus akan menikmatinya.

Rasa nasionalis Chairil yang begitu tinggi tergambar pada bait pertama: //Di masa pembangunanini// Tuan hidup kembali//dan bara kagum menjadi api//. Chairil Anwar melihat betapa pangeran "Diponegoro" begitu bergairah dan bersemangat dalam usaha membela bangsanya. Tanpa ragu dan gentar ia berjuang hanya dengan pedang dan keris melawan Belanda.

//Di depan sekali tuan menanti//Tak gentar/Lawan banyaknya seratus kali//Pedang di kanan keris di kiri/Berselempang semangat yang tak bisa mati//

Bait kedua tersebut menunjukkan, betapa besar perjuangan "Pangeran Diponegoro."

Walaupun tidak didukung oleh kekuatan militer yang terlatih perang, namun hanya dengan semangat nasionalis, semangat juang, ia dan pasukan rakyatnya tak gentar melawan musuh.

//Dan bara kagum menjadi api//. Larik ketiga bait pertama puisi di atas menggambarkan semangat juang Diponegoro, seorang pangeran yang tegak dengan angkuhnya menghadapi musuh. //Ini barisan tak bergenderang berpalu//Kepercayaan tanda menyerbu//

Bait ketiga puisi di atas menggambarkan tentang pasukan Diponegoro yang memancarkan semangat dan kekuatan besar tak gentar melawan musuh. Dengan mengandalkan rasa nasionalis, kesetiakawanan, saling percaya, bersatu menentang pasukan lawan yang menghadang di depan.

Hidup manusia bukan sekedar hidup tapi hidup harus diisi dengan arti. Hidup harus dihubungkan dengan sesuatu yang lebih besar dari hidup itu sendiri. Dihubungkan dengan konteks dan teks puisi "Diponegoro", jelas telihat dan terasa semangat nasionalis, jelas terlihat perjuangan Pangeran Diponegoro untuk memerdekakann negerinya.

\section{//Bagimu negeri menyediakan api//}

Bait keempat puisi tersebut Chairil Anwar mengatakan bahwa Diponegoro berjuang untuk tanah airnya (Jawa) yang mengacu pada kemerdekaan negara Indonesia. Rasa nasionalis yang bergelora dalam sanubarinya melawan kaum penjajah, walaupun nyawa melayang, ia tetap tegak dan tegar menghadapi lawan yang tak terhitung jumlahnya demi kemerdekaan negeri dalam konteks negara Indonesia.

Chairil mewakili sifat nasionalis Diponegoro, ia tidak mau hidup dalam jajahan lawan. Lihatlah bait kelima berikut: //Punah di atas menghamba/Binasa di atas ditindas//

Dua larik di atas menunjukkan kebulatan tekad Chairil yang mewakili Diponegoro dalam membela bangsa dan tanah airnya. Keberanian, kepahlawanan, patriotisme Diponegoro diekspresikan Chairil pada bait keenam://maju//, //serbu//, //serang//, //terjang//; menunjukkan betapa yakinnya Diponegoro sebagai seorang pangeran melawan para musuh yang ada di depannya.Lewat puisi"Diponegoro", Chairil Anwar mengimbau pada generasi muda untuk menghayati kembali semangat nasionalis, semangat perjuangan Diponegorodan menerapkannya di era pembangunan dan teknologi sekarang ini. Sebagai generasi penerus bangsa kita harus memiliki sikap nasionalis yang tinggi, semangat memperjuangkan kemerdekaan dan keadilan bangsa dan negara tercinta ini.

Puisi "Diponegoro" diciptakan Chairil Anwar pada tahun 1943. Pada tahun tersebut Indonesia sedang dijajah Jepang. Dalam puisi tersebut sarat dengan unsur propaganda. Kata-kata yang merujuk propaganda adalah 'bara', 'api', 'semangat', 'kepercayaan', 'maju', 'serbu, 'serang', dan 'terjang'. Ada pula beberapa frasa yang merujuk propaganda 
yaitu 'sekali berarti', 'sudah itu mati', 'bagimu negeri', dan 'menyediakan api'. Pemilihan kata tersebut merupakan penanda dan pelecut semangat nasionalis. Jika dilihat konteks zaman puisi tersebut dibuat, puisi tersebut berfungsi sebagai propaganda. Penyair ingin menyampaikan semangat nasionalismenya untuk melakukan perlawanan terhadap penjajah. Semangat-nasionalisme tersebut sangat jelas terlihat dari pemilihan kata. Pemilihan kata yang dilakukan penyair cenderung tak berimbuhan. Pemilihan kata tersebut cenderung mengisyaratkan ketegasan. Dalam memberi semangat nasionalisme melalui media puisi Chairil mengangkat tokoh pahlawan Diponegoro yang sangat tegas dan berapi-api karena dalam melawan penjajah Diponegoro rela berkorban, berani mati, serta memiliki semangat tinggi. //Sekali berarti, sudah itu mati//

PangeranDiponegoro adalah patriot bangsa yang pantas untuk diteladani. Di masa pembangunan ini semangat perjuangan Pangeran Diponegoro harus dihidupkan kembali di dalam jiwa kita;//Tuan hidup kembali/dan bara kagum menjadi api//.

Chairil melihat betapa Pangeran Diponegoro begitu berani mempertahankan hidup ini.Tanpa rasa takut, tanpa rasa bimbang, seakan kan semua persoalan hidup ini sudah terjawab. "Di depan sekali tuan menanti. /Takgentar// Lawan banyaknya seratus kali//Pedang di kanan/keris di kiri// Berselempang semangat yang takbisa mati//. Larik larik ini juga menunjukkan perjuangan Pangeran Diponegoro yang tidak hanya didukung oleh kekuatan grilya yang terlatih (pedang) tetapi juga oleh kekuatan rakyat yang sesuai tradisi menggunakan keras.Melihatsemuaini, Chairilmudahanyabis aberkata: //Dan barakagum menjadi api//. Chairil sebagai seorang pemuda yang sedang bimbang dan berpikir keras, sekarang berhadapan dengan seorang pangeran yang tegak dengan angkuhnya menghadapi hidup ini.

\section{kekuatan engandalkan semangat nasionalis, kesetiakawanan, dan saling mempercayai (kepercayaan tanda penyerbu). Hidup bukanlah sesuatu yang harus dipertahankan hanya supaya jangan mati. Hidup adalah sesuatu yang harus diisi dengan arti. Hidup}

Pasukan Diponegoro memancarkan akan cukup berharga kalau dia punya arti, meski tuhanya dapat diberikan satu kali. Hidup harus dikaitkan dengan sesuatu yang lebih besar dari hidup itu sendiri, yaitu kemerdekaan negerinya. Dalam keadaan seperti itu, kematian yang menjadi pikiran yang terus menerus datang mengganggu Chairil, tampak tidak berarti, karena kehidupan itu sendiri sudah tidak menjadi inti persoalan lagi, melainkan hanya tinggal bagian kecil dari suatu yang lebih besar itu. Karena itu, meskipun tahu bahwa dia akan kehilangan hidupnya, Sang Pangeran tetap tegak "takgentar" di hadapan "lawan banyaknya seratus kali". Karena kemerdekaan adalah lebih tinggi dari kehidupan itu sendiri.

Apa yang diperjuangkan Sang Pangeran? //Bagimu, egeri menyediakan api//, katanya. Diponegoro berjuang untuk tanah airnya, yang identik dengan kemerdekaan. Lebih baik punah dari pada hidup menghamba, lebih baik binasa dari pada hidup tertindas.

Bait terakhir puisi "Diponegoro" menunjukkan kebulatan tekad para patriot untuk membela bangsa dan tanah air seperti berikut ini: maju/ serbu/ serang/ terjang/. Penyair melihat bahwa para patriot bangsa tidak mempunyai pilihan lain dalam menghadapi penjajah kecuali maju untuk menyerbu, menyerang, dan menerjang musuh.

\section{Unsur Historis \\ Perang Jawa (Java War).}

Puisi "Diponegoro" tidak terlepas dengan peristiwa sejarahmasa lampau yaitu perlawanan rakyat di Jawa dalam menentang kolonial Belanda.Dalam sejarah Indonesia dikenal dengan Perang Diponegoro (18251830) atau dalam literatur asing disebut Java war.Pada sekitar abad ke 18, penjajah Hindia Belanda dengan melalui perusahaan dagangnya VOC (Verenigde Oost indische Compagnie) sedang melebarkan kekuasaannya untuk mengelolah dan memiliki perkebunan rakyat terutama rempah rempah dan beras diseluruh Indonesia termasuk di Jawa \& Sulawesi - Maluku.Pada waktu itu di Jawa berdiri satu kerajaan Jawa peninggalan Kerajaan Mataram yakni Kerajaan Jogyakarta termasuk daerah Surakarta (Solo) dan diberi namaKesultanan.Orang pertama yang menjabat sebagai Sultan adalah Hamengkubuwono I, dan pada masa terjadi perang Diponegoro maka Jogyakarta dipimpin 
oleh Sultan Hamengkubuwono V.Penjajah Belanda melihat, karena Jogyakarta pada waktu itu sebagai lumbung beras utama di Jawa, maka harus dikuasai melalui VOC, dan terjadilah pematokan persawahan milik rakyat, yang kemudian diklaim sebagai milik pemerintah penjajah

Salah satu pangeran dari kesultanan Jogyakarta pada waktu,Pangeran Diponegoro tidak tahan dan emosi melihat rakyatnya diperlakukan demikian oleh Belanda. Pangeran Diponegoro dengan nama lahir Raden Mas Ontowirjo adalah putra sulung dari Sultan Hamengku Buwono III, lahir 11 November 1785. Emosi Pangeran Diponegoro tak terbendung ketika pematokan dilaksanakan Belanda pada sawah sawah rakyat.Apalagi pematokan itu melintasi kompleks pemakaman bekas raja- raja Jawa, sekaligus merupakan makam para leluhurnya.Rakyat yang mempergunakan jalan sebagai transportasi perdagangan dibebankan pajak yang tinggi oleh Belanda.Pada waktu itu yang menjadi Raja (Sultan) Jogyakarta adalah Sultan Hamengkubuwono V yang dinobatkan ketika baru berumur 3 tahun. Jadi untuk sementara pemerintahan dijalankan oleh kerabat Keraton Hamangku Buwono IV.Pemeritah sementara kesultanan ini tidak berdaya, karena ternyata kekuasaan yang sebenarnya terselubung dan berkolobarasi dengan pemerintah Kolonial Belanda. Selanjutnya, Pangeran Diponegoro menyusun rencana untuk melawan penjajahan Belanda.

Beberapa saat kemudian pada tahun 1825 berkobarlah Perang Jawa / Perang Diponegoro melawan penjajahan Belanda.Perang tersebut sangat sulit diatasi Belanda walaupun memakan korban yang cukup besar dikedua belah pihak. Perang ini berlangsung hampir 5 tahun.Perang Jawa ini menelan korban dipihak pemerintah Hindia sebanyak 8.000 serdadu berkebangsaan Eropa, 207.000.pribumi/ orang Jawa,sehingga mengakibatkan penyusutan penduduk Jawa pada waktu itu. Sentot Prawirodirdjo berhasil dibujuk Belanda, meletakkan senjata pada tanggal 17 Oktober 1829, dan dikirim Belanda ke Sumatra Selatan untuk melawan pembrontakan para ulama dalam perang "Padri". Beliau wafat di Bengkulu pada tanggal 17 April 1855 dalam usia 48 tahun. Jendral De Cock naik pitam oleh karena walaupun dia punya banyak serdadu akan tetapi dia tidak bisa memadamkan pemberontakan itu. Akhirnya De Cock mendapat kecaman dari atasannya di Batavia (Jakarta). Suatu saat selagi perang berkecamuk Pangeran Diponegoro terluka tertembus peluru, yang kemudian beliau menunjuk Kyai Mojo sebagai Panglima Perang dan Pangeran Mangkubumi sebagai Komandan Lapangan. (Noviandi,h, 2012)

\section{Penangkapan Pangeran Diponegoro}

Perundingan tidak mencapai kesepakatan, dan pada saat itulah Pangeran Diponegoro ditangkap oleh pasukan Belanda pimpinan de Kock. Pangeran Diponegoro ditawan, lalu dibawa ke Ungaran Semarang, kemudian ke Batavia.Pada 8 April 1830 Pangeran Diponegoro sampai di Batavia (Jakarta) dan ditempatkan di Stadhuis,penjara bawah tanah (Museum Fathahilah sekarang). Penjara bawah tanah ini dilengkapi dengan rantai besi dengan bandul-bandul besi bulat yang cukup berat agar para tahanan tak bisa melarikan diri.Tinggi pintu masuk penjara ini 1.50.meter sedangkan ruangan yang berbentuk terowongantingginya hanya 1 meter sehingga tahanan harus membungkuk di dalamnya. Diponegoro, Kiay Mojo dan para pengikut dipenjarakan Belanda di tempat ini selama 25 hari.

Kemudian pada 3 Mei 1830 Pangeran Diponegoro dan rombongannya diberangkatkan dengan kapal perang Pollux ke Manado.Pengikut-pengikut Diponegoro semuanya kaum pria karena tek satupun wanita yang diikut sertakan.Sebelum tiba ke tempat pengasingan, rombongan Diponegoro diberhentikan, menunggu di sebuah pelabuhan kecil Kema yaitu Tanjung Merah Minahasa, sebelah utara pelabuhan Kema.Kemudian dilanjutkan ke Menado.Di Manado ditempatkan di Benteng Amsterdam selama 4 tahun.Pangeran Diponegoro oleh Belanda tidak disatukan dengan Kyai Modjo di Tondano karena dianggap Belanda sangat berbahaya.ketika di Manado, Diponegoro hanya sekali saja sempat bertemu dengan Kiay Modjo dan mendirikan mesjid pertama di perkampungan baru yang bernama Tegal Rejo (batas perkampungan Tondano dan Tonsea Lama). Mesjid tersebut diberi nama "Mesjid diponegoro". Oleh karena Belanda menganggap penjagaan di Manado tidak cukup kuat, apalagi Pangeran Diponegoro 
ketika di penjara menampar Residen Gambier, maka Pangeran Diponegoro dipindahkan lagi di Benteng Rotterdaam Makassar pada tahun 1834. Beliau wafat pada 8 Februari 1855 dalam usia 78 tahun.

\section{SIMPULAN}

Puisi "Diponegoro" merupakan puisi yang bertemakan pejuangan. Dalam hal ini, perjuangan Diponegoro adalah perjuangan melawan kolonialisme. Rasa nasionalis, rasa cinta taat, dan setia kepada tanah air, menyebabkan Diponegoro melakukan perlawanan karena ingin membebaskan negara dan bangsanya dari penguasaan dan cengkaman kuasa asing dalam hal ini Belanda.

Puisi "Diponegoro" tidak terlepas dari peristiwa sejarah Indonesia yang dikenal dengan Perang Diponegoro (1825-1830) atau dalam literatur asing disebut Java war. Fakta sejarah membuktikan, sekitar abad ke- 18, penjajah Hindia Belanda dengan melalui perusahaan dagangnya VOC (Verenigde Oost indische Compagnie) melebarkan kekuasaannya untuk mengelola dan memiliki perkebunan rakyat terutama rempah- rempah dan beras di seluruh Indonesia termasuk di Jawa, Sulawesi dan Maluku.

\section{DAFTAR PUSTAKA}

Abdullah, Taufik. (1987): Sejarah dan Masyarakat. Jakarta,Pustaka Firdaus

Anwar, Chairil. (1977). Deru Campur Debu. Jakarta : Pustaka Rakyat

Kartodirdjo, Sartono. (1993). Pendekatan Ilmu Sosial dalam Metodologi Sejarah, Yogyakarta: Gajah Mada University Press

Koentjaraningrat. (1993) Masalah Kesukubangsaaan dan Integrasi Nasional. Jakarta: UI Press

Louis Gottshalk, (2005). Understanding History: A Primer of Historical Method, New Jesey: Pearson Education

Kuntowijoyo. (1994) :Metodologi Sejarah, Yogyakarta: Tiara Wacana

Kuntowijoyo. (1991) Paradigma Islam Interpretasi untuk Aksi, Bandung: Mizan.

Manuhutu, E. (1996) Timbulnya Kombinasi yang Harmonis antara Unsur-Unsur Kebudayaan Minahasa dan Jawa sejak Abad XV, dalam Yapenra, nomor II tahun III Pebruari

Sakhwi Abd. Ar Rahman. (1997). Historiografi Islam, Jakarta: Logos Wacana Ilmu 